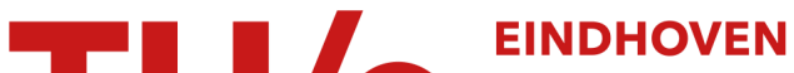 UNIVERSITY OF TECHNOLOGY
}

\section{Ordering of quantum dot molecules by self-organization}

\author{
Citation for published version (APA): \\ Lippen, van, T., Nötzel, R., \& Wolter, J. H. (2005). Ordering of quantum dot molecules by self-organization. \\ Journal of Vacuum Science and Technology, B, 23(4), 1693-1699. https://doi.org/10.1116/1.1942510
}

DOI:

10.1116/1.1942510

Document status and date:

Published: 01/01/2005

\section{Document Version:}

Publisher's PDF, also known as Version of Record (includes final page, issue and volume numbers)

\section{Please check the document version of this publication:}

- A submitted manuscript is the version of the article upon submission and before peer-review. There can be important differences between the submitted version and the official published version of record. People interested in the research are advised to contact the author for the final version of the publication, or visit the $\mathrm{DOI}$ to the publisher's website.

- The final author version and the galley proof are versions of the publication after peer review.

- The final published version features the final layout of the paper including the volume, issue and page numbers.

Link to publication

\section{General rights}

Copyright and moral rights for the publications made accessible in the public portal are retained by the authors and/or other copyright owners and it is a condition of accessing publications that users recognise and abide by the legal requirements associated with these rights.

- Users may download and print one copy of any publication from the public portal for the purpose of private study or research.

- You may not further distribute the material or use it for any profit-making activity or commercial gain

- You may freely distribute the URL identifying the publication in the public portal.

If the publication is distributed under the terms of Article 25fa of the Dutch Copyright Act, indicated by the "Taverne" license above, please follow below link for the End User Agreement:

www.tue.nl/taverne

Take down policy

If you believe that this document breaches copyright please contact us at:

openaccess@tue.nl

providing details and we will investigate your claim. 


\title{
Ordering of quantum dot molecules by self-organization
}

\author{
Twan van Lippen, ${ }^{\text {a) }}$ Richard Nötzel, and Joachim H. Wolter \\ eiTT/COBRA Inter-University Research Institute, Eindhoven University of Technology, \\ 5600 MB Eindhoven, The Netherlands
}

(Received 25 January 2005; accepted 19 March 2005; published 25 July 2005)

\begin{abstract}
Ordered groups of InAs quantum dots (QDs), lateral QD molecules, are created by self-organized anisotropic strain engineering of a (In,Ga)As/GaAs superlattice (SL) template on GaAs (311)B by molecular beam epitaxy. During stacking the SL template self-organizes into a highly ordered two-dimensional (In,Ga)As and, thus, strain field modulation on a mesoscopic length scale, constituting a Turing pattern in solid state. InAs QDs preferentially grow on top of the SL template nodes due to local strain recognition, forming a lattice of separated groups of closely spaced ordered QDs. The SL template and InAs QD growth conditions like the number of SL periods, growth temperatures, amount and composition of deposited (In, Ga)As, and insertion of Al-containing layers are studied in detail for optimized QD ordering within and among the InAs QD molecules on the SL template nodes, which is evaluated by atomic force microscopy. The average number of InAs QDs within the molecules is controlled by the thickness of the upper GaAs separation layer on the SL template and the (In,Ga)As growth temperature in the SL. The strain correlated growth in SL template formation and QD ordering is directly confirmed by high-resolution x-ray diffraction. Ordered arrays of single InAs QDs on the SL template nodes are realized for an elevated SL template and InAs QD growth temperature together with the insertion of a second InAs QD layer. The InAs QD molecules exhibit strong photoluminescence (PL) emission up to room temperature. Temperature dependent PL measurements exhibit an unusual behavior of the full width at half maximum, indicating carrier redistribution solely within the QD molecules. (C) 2005 American Vacuum Society. [DOI: 10.1116/1.1942510]
\end{abstract}

\section{INTRODUCTION}

One of the most challenging prerequisites to be fulfilled for the realization of future quantum functional devices with applications in solid state quantum computing and quantum communication is lateral ordering of semiconductor quantum dots (QDs) of high quality in well-defined arrangements. ${ }^{1}$ The self-assembly in the Stranski-Krastanov (SK) growth mode can produce QDs of high structural and optical quality which are, however, usually randomly distributed on the wafer surface. To control the QD sites, epitaxial growth on artificially patterned substrates has been widely investigated ${ }^{2-4}$ which, however, imposes strong limitations due to the spatial resolution of the lithography and/or etching steps, and easily introduces size fluctuations and defects in the QDs. To overcome these limitations, we have developed a concept for the lateral ordering of QDs in one- and two-dimensional arrays by molecular beam epitaxy (MBE) on planar GaAs (100) substrates, ${ }^{5,6}$ which has been reproduced later in Ref. 7, and planar GaAs (311)B (Ref. 8) substrates. The concept is based on self-organized anisotropic strain engineering of (In,Ga)As/GaAs superlattice (SL) templates and the lateral ordering of (In,Ga)As QDs by local strain recognition. It benefits from the inherent smoothness of the lateral strain field modulations generated on the SL template surfaces on the nanometer length scale, producing ordered QD arrays of excellent structural and optical quality.

${ }^{\text {a)} E l e c t r o n i c ~ m a i l: ~ t . v . l i p p e n @ t u e . n l ~}$
Here we concentrate on the creation of an ordered lattice of lateral InAs QD molecules by self-organized anisotropic strain engineering of a (In,Ga)As/GaAs SL template on GaAs (311)B substrates. ${ }^{8,9}$ Starting from a nanoscale modulated (In,Ga)As layer, subsequent thin GaAs capping, annealing, GaAs overgrowth, and repetition in SL growth produces a highly ordered, two-dimensional (In, Ga)As and, thus, strain field modulation on a mesoscopic length scale. It constitutes a Turing pattern in solid state, which is stable after ten SL periods. When InAs QDs are grown on this strain modulated template, they arrange into ordered groups of laterally closely spaced QDs on top of the SL template nodes, forming an ordered lattice of isolated QD molecules. The QD molecules exhibit the highest degree of ordering for slightly reduced InAs growth temperature and medium total strain, i.e., In composition and thickness of the (In,Ga)As layers in the SL template, as evaluated by atomic force microscopy (AFM). Insertion of Al-containing layers in the SL template inhibits the evolution of strain modulation and InAs QD ordering due to suppressed lateral mass transport. The average number of InAs QDs within the molecules is controlled by the thickness of the upper GaAs separation layer on the SL template, and the growth temperature of the (In,Ga)As and thin GaAs cap layers in the SL. For optimized SL template formation the strain correlated growth and QD ordering are consistently confirmed by high-resolution X-ray diffraction (XRD) in various scattering geometries. Ordered arrays of single InAs QDs on the SL template nodes are realized at elevated temperatures for SL template formation 


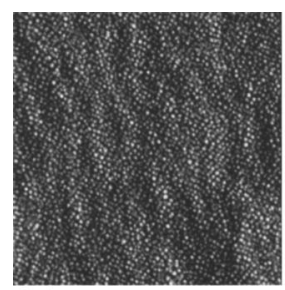

(a)

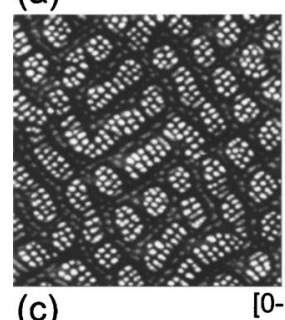

$[-233]$
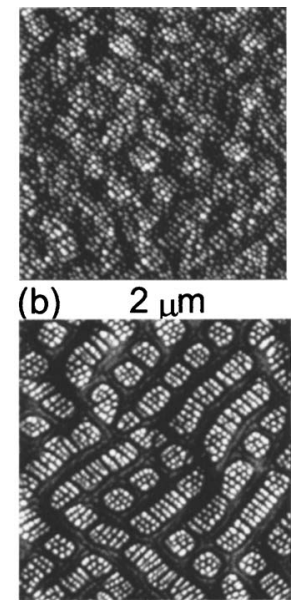

(d)

FIG. 1. AFM images of $3.2 \mathrm{~nm}(\mathrm{In}, \mathrm{Ga})$ As on the (a) 1-, (b) 5-, (c) 10-, and (d) 15- period SL templates. The scan field is $2 \times 2 \mu \mathrm{m}^{2}$ and the black-towhite height contrast is $15 \mathrm{~nm}$ for all images.

and InAs QD growth together with the insertion of a second InAs QD layer. The QD molecules exhibit excellent photoluminescence (PL) properties up to room temperature (RT). Temperature dependent PL measurements exhibit an unusual behavior of the full width at half maximum (FWHM), indicating carrier redistribution solely within the QD molecules.

\section{EXPERIMENTAL DETAILS}

The samples were grown by solid source MBE on GaAs (311)B substrates. After deposition of a $250 \mathrm{~nm}$ thick GaAs buffer at $580{ }^{\circ} \mathrm{C}$, the samples were cooled down for (In,Ga)As/GaAs SL growth. If not mentioned otherwise, each SL period comprised $3.2 \mathrm{~nm} \operatorname{In}_{0.37} \mathrm{Ga}_{0.63} \mathrm{As}$ grown at $500{ }^{\circ} \mathrm{C}$, thin capping by $0.7 \mathrm{~nm} \mathrm{GaAs}$ at $500{ }^{\circ} \mathrm{C}$, annealing for $2 \mathrm{~min}$ at $580^{\circ} \mathrm{C}$, and growth of a $5.5 \mathrm{~nm} \mathrm{GaAs}$ spacer layer at $580^{\circ} \mathrm{C}$. The number of SL periods was between 1 and 15 in different samples. The growth rates of GaAs and $\mathrm{In}_{0.37} \mathrm{Ga}_{0.63} \mathrm{As}$ were 0.073 and $0.116 \mathrm{~nm} / \mathrm{s}$. In further experiments, the In composition of the (In,Ga)As SL template layers was varied between $25 \%$ and $45 \%$, and the (In, Ga)As thickness between 3.0 and $5.0 \mathrm{~nm}$. For InAs QD formation on the ten-period SL template, the growth temperature was varied between 450 and $520^{\circ} \mathrm{C}$, and the upper GaAs separation layer thickness from 5.5 to $20 \mathrm{~nm}$. InAs was deposited to a nominal thickness of $0.5-0.6 \mathrm{~nm}$ at a growth rate of $0.0013 \mathrm{~nm} / \mathrm{s}$. The structural properties of the InAs QDs and SL templates were characterized by AFM and XRD in air. For the PL studies the QDs were capped by $200 \mathrm{~nm}$ GaAs $(20 \mathrm{~nm}$ at the InAs QD growth temperature plus $180 \mathrm{~nm}$ at $580^{\circ} \mathrm{C}$ without annealing). The PL was excited by the 512 $\mathrm{nm}$ line of a Nd-YAG laser with a power density of $0.2 \mathrm{~W} / \mathrm{cm}^{2}$. For the temperature dependent PL measurements a He-flow cryostat was used to control the temperature between 5 and $300 \mathrm{~K}$.
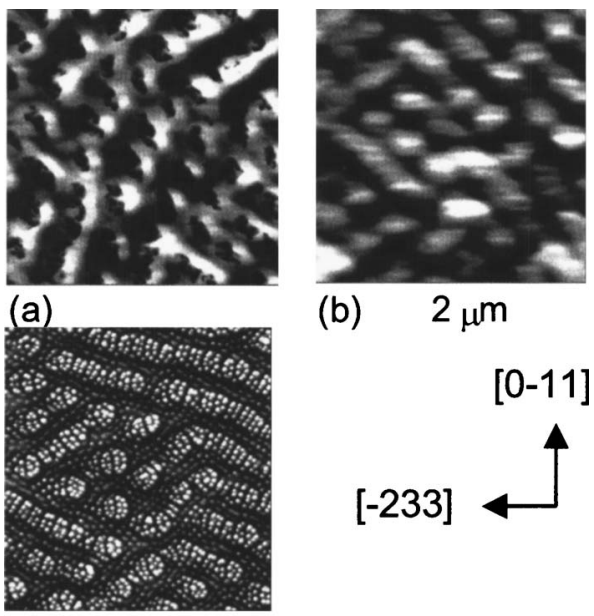

(b) $2 \mu \mathrm{m}$

(c)

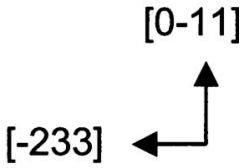

FIG. 2. (a), (b) AFM images of the $0.7 \mathrm{~nm}$ GaAs cap layer after annealing and of the subsequent $5.5 \mathrm{~nm} \mathrm{GaAs}$ spacer layer of the 11th SL period. (c) AFM image of $3.2 \mathrm{~nm}$ (In,Ga)As on the 10-period SL template, where the growth temperature of the (In, Ga)As layers and thin GaAs cap layers is increased to $550{ }^{\circ} \mathrm{C}$, and the temperature for annealing and $\mathrm{GaAs}$ spacer layer growth to $610^{\circ} \mathrm{C}$. The scan field is $2 \times 2 \mu \mathrm{m}^{2}$ for all images and the black-to-white height contrast is $4 \mathrm{~nm}$ for (a) and (b), and $15 \mathrm{~nm}$ for (c).

\section{SL TEMPLATE EVOLUTION AND STABILITY}

Figure 1 shows the AFM images of the $3.2 \mathrm{~nm}$ $\mathrm{In}_{0.37} \mathrm{Ga}_{0.63} \mathrm{As}$ layers on the (In,Ga)As/GaAs SL templates with (a) 1, (b) 5, (c) 10, and (d) 15 periods. For this In composition, single (In,Ga)As layers on GaAs (311)B develop a nanoscale two-dimensional surface modulation due to strain driven growth instability, rather than nucleation of QDs in the SK mode, which occurs for higher In composition. ${ }^{10}$ They constitute a layer of connected QDs due to nucleationless, continuous increase of the modulation height as a function of the layer thickness with a constant lateral periodicity. This is observed for the (In,Ga)As layer on the one-period SL template. On the other hand, for the five-and ten- period SL templates, distinct ordering into a two-dimensional mesoscopic mesa-like arrangement is observed. Most important, the mesoscopic surface pattern becomes stable after ten SL periods for the present growth conditions. This is revealed in Fig. 1(d) for the (In,Ga)As layer on the 15-period SL template, which closely resembles that on the ten-period SL template in Fig. 1(c). The average mesa width amounts to $200 \mathrm{~nm}$ with a lateral periodicity of $300 \mathrm{~nm}$ and a height of $8-10 \mathrm{~nm}$.

The different steps in formation of the 11th SL period are shown in Figs. 2(a) and 2(b). After thin $(0.7 \mathrm{~nm})$ GaAs capping of the (In,Ga)As layer and annealing [Fig. 2(a)], a twodimensional mesoscopic surface modulation with a reduced height of 3-4 nm is observed. The nodes are smooth with a lateral periodicity of again $300 \mathrm{~nm}$. After $5.5 \mathrm{~nm} \mathrm{GaAs}$ spacer layer growth [Fig. 2(b)] the overall surface becomes very smooth maintaining a similar modulation height. Thus the formation mechanism of the SL template is described as follows. The nanoscale two-dimensional surface modulation of the first (In,Ga)As layer already shows a preferential or- 
dering along the directions plus and minus $45^{\circ}$ off [0-11], most probably due to lateral strain coupling through the substrate and/or preferential anisotropic surface migration in these directions. After thin GaAs capping and annealing this morphology is smoothened and, again due to lateral strain coupling and anisotropic surface migration the mesoscopic ordering builds up. It organizes itself into the well-defined mesa-like structure during SL growth due to preferential, strain correlated (In, Ga)As growth on its nodes, which is governed by strain-gradient driven In adatom migration toward the tensile strain field minima generated by the accumulated $(\mathrm{In}, \mathrm{Ga})$ As underneath. This is evident from the larger mesa height of 8-10 $\mathrm{nm}$ after (In,Ga)As deposition [Fig. 1(c)] compared to that of the GaAs spacer layer of 3-4 nm [Fig. 2(b)].

The morphology in Fig. 1(c) constitutes the Turing pattern $^{11}$ of buried (In,Ga)As quantum disks obtained by metal organic vapor-phase epitaxy (MOVPE) ${ }^{12}$ In contrast to MOVPE, where the strain driven materials reorganization is completed for the first $(\mathrm{In}, \mathrm{Ga})$ As layer due to the higher growth temperature, the development of the SL template in MBE provides snapshots of the pattern evolution, which have been rarely observed experimentally. ${ }^{13}$ Within the general description of reaction-diffusion systems, in the present case, the reaction term may be associated with strain induced island formation during (In,Ga)As growth and the diffusion term with adatom surface migration during annealing and (In, Ga)As growth, guided by the lateral strain field modulation. This is supported by altering the balance between reaction and diffusion when the temperature for $(\mathrm{In}, \mathrm{Ga}) \mathrm{As}$ growth and thin $\mathrm{GaAs}$ capping is increased to $550{ }^{\circ} \mathrm{C}$, and the temperature for annealing and GaAs spacer layer growth to $610^{\circ} \mathrm{C}$. This reduces the strain due to enhanced In desorption and increases the adatom surface migration length. As a result, the mesa-like pattern aligned plus and minus $45^{\circ}$ off [0-11] transforms into a zigzag or stripelike pattern oriented preferentially along the directions $\sim 70^{\circ}$ off $[0-11]$, as shown in Fig. 2(c). A quantitative analysis of the pattern formation and pattern transition ${ }^{13}$ as a function of growth conditions is, however, beyond the scope of the present evaluation.

\section{INAS QD MOLECULES: FORMATION}

InAs QDs grow on top of the SL template (i.e., on the upper GaAs layer) in dense and well-separated ordered groups. Figure 3(a) shows the AFM image of the QD molecules formed by $0.6 \mathrm{~nm}$ InAs deposited at $500{ }^{\circ} \mathrm{C}$ on the ten-period SL template of Fig. 2(b). The QDs arrange on the nodes of the SL template where the underlying (In,Ga)As accumulation establishes the tensile strain field minima and the related strain-gradient driven In adatom migration for strain correlated stacking. ${ }^{5-9}$ The ordering and size uniformity of the InAs QDs within the groups are significantly improved by lowering the InAs growth temperature to $470{ }^{\circ} \mathrm{C}$ [see the $0.5 \mathrm{~nm}$ InAs QD molecules in Fig. 3(b)] and can certainly be improved further by optimizing other growth parameters, such as growth rate and V/III ratio. When the temperature is lowered further to $450{ }^{\circ} \mathrm{C}$ the QD ordering
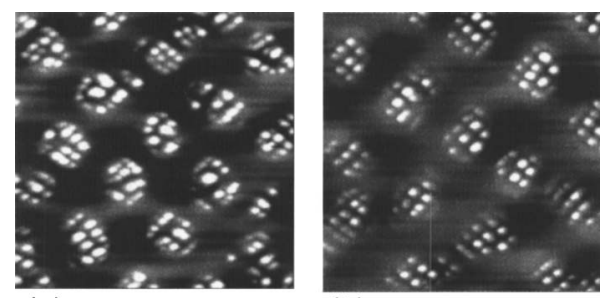

(a)

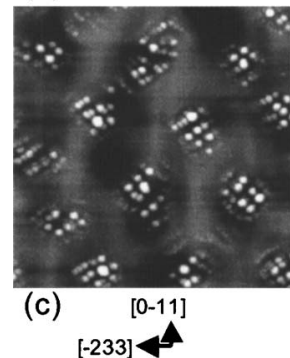

(b)

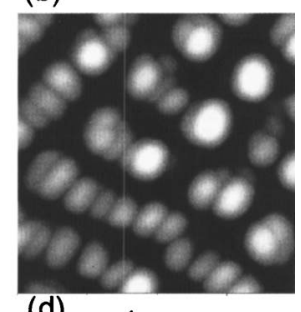

(d) $1 \mu \mathrm{m}$

FIG. 3. AFM images of the InAs QDs grown at (a) $500{ }^{\circ} \mathrm{C}$, (b) $470{ }^{\circ} \mathrm{C}$, (c) $450{ }^{\circ} \mathrm{C}$, and (d) $520^{\circ} \mathrm{C}$ on the ten-period SL template. The scan field is 1 $\times 1 \mu \mathrm{m}^{2}$ for all images and the black-to-white height contrast is $10 \mathrm{~nm}$ for (a)-(c) and $20 \mathrm{~nm}$ for (d).

decreases for too small In adatom migration length [Fig. $3(\mathrm{c})]$. For an InAs growth temperature of $520^{\circ} \mathrm{C}$ large, elongated mounds are observed in Fig. 3(d), indicating coalescence of the QDs, which is already recognized in Fig. 3(a) for the QDs grown at $500{ }^{\circ} \mathrm{C}$ in the center of the nodes. Hence, a growth temperature of $470{ }^{\circ} \mathrm{C}$ is identified for optimum InAs QD ordering within the molecules while the ordering is decreased at a higher temperature due to QD coalescence and at a lower temperature due to too small In adatom migration length.

\section{SL TEMPLATE PROPERTIES: IN COMPOSITION AND THICKNESS}

The In composition and thickness of the (In, Ga)As layers in the ten-period SL template are varied to gain further insight in the SL template evolution for QD ordering. ${ }^{9}$ The two-dimensional strain field modulation and, hence, (In,Ga)As distribution of the SL template is probed by the location of the optimized InAs QDs grown at $470{ }^{\circ} \mathrm{C}$ on top. Regarding the In composition, the highest degree of ordering of the QD molecules in well-separated and ordered groups is observed in a window between $37 \%$ and $29 \%$, when adjusting the respective (In,Ga)As layer thickness to 3.2 and 4.0 $\mathrm{nm}$ to keep the total amount of In constant [see Figs. 4(a) and 4(b), respectively].

Increasing the (In,Ga)As layer thickness to $4.0 \mathrm{~nm}$ for an In composition of $37 \%$ [Fig. 4(c)], or increasing the In composition to $45 \%$ for a layer thickness of $3.0 \mathrm{~nm}$ [Fig. 4(d)] leads to less separated QD molecules with more and smaller disordered QDs per group. Also for the low In composition of $25 \%$ and $5.0 \mathrm{~nm}(\mathrm{In}, \mathrm{Ga})$ As layer thickness [Fig. 4(e)], disorderly connected QD groups are produced together with larger InAs clusters. Therefore, the highest degree of ordering of the QD molecules is achieved at medium total strain, i.e., In composition and thickness of the (In,Ga)As layers in 

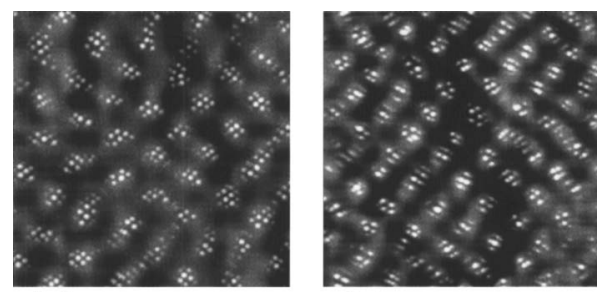

(a)

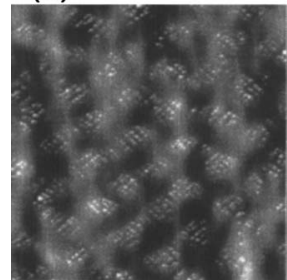

(c)

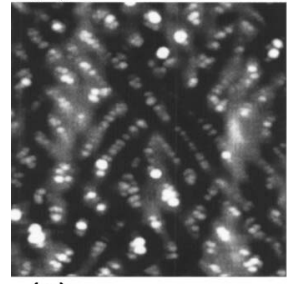

(b)

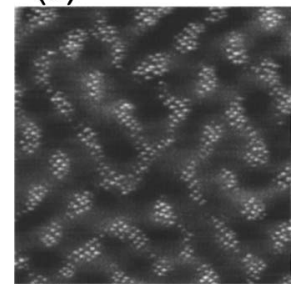

(d) $2 \mu \mathrm{m}$

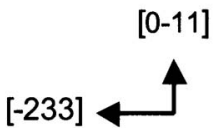

(e)

FIG. 4. AFM images of the InAs QDs grown at $470{ }^{\circ} \mathrm{C}$ on the ten-period SL template with (In,Ga)As layers of (a) $37 \%(3.2 \mathrm{~nm})$, (b) $29 \%(4.0 \mathrm{~nm}),(\mathrm{c})$ $37 \%(4.0 \mathrm{~nm}),(\mathrm{d}) 45 \%(3.0 \mathrm{~nm})$, and (e) $25 \%(5.0 \mathrm{~nm})$ In composition and thickness. The scan field is $2 \times 2 \mu \mathrm{m}^{2}$ and the black-to-white height contrast is $15 \mathrm{~nm}$ for all images.

the SL template. Too large total strain opposes the buildup of sufficient (In, Ga)As accumulation on the SL template nodes and, hence, magnitude of the lateral strain field modulation, leading to less separated QD groups with more and smaller QDs of low internal ordering. Similarly, for too low total strain, a more homogeneous (In,Ga)As layer is maintained and the strain correlated stacking for formation of welldefined SL template nodes and lateral strain field modulation is not supported.

\section{SL TEMPLATE PROPERTIES: AL-CONTAINING LAYERS}

Inserting AlAs-containing layers at various locations in the GaAs spacer layers of the SL template significantly alters its formation and the QD ordering. ${ }^{9}$ The total spacer layer thickness is kept at $5.5 \mathrm{~nm}$. Depositing two monolayers (MLs) AlAs on top of the SL template directly underneath the InAs QDs leads to more and smaller QDs per group with less ordering and a significant number in between [Fig. 5(a)]. This is attributed to a decrease of the In adatom migration length on AlAs. When 2 MLs AlAs covered by $1.0 \mathrm{~nm} \mathrm{GaAs}$ are introduced beneath each (In, Ga)As layer of the SL template and the InAs QDs on top, a rather smooth mesalike morphology is observed, superimposed by shallow elongated QDs [Fig. 5(b)]. Incorporation of 2 MLs AlAs on top of the thin GaAs cap layer after annealing in each SL period results in mesas covered with shallow InAs QDs and a small number of large InAs clusters [Fig. 5(c)]. Replacing the whole

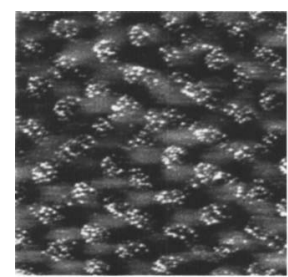

(a)

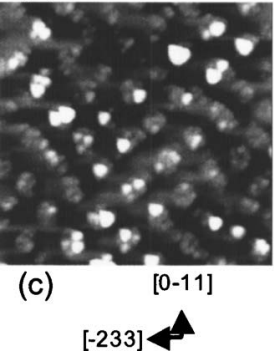

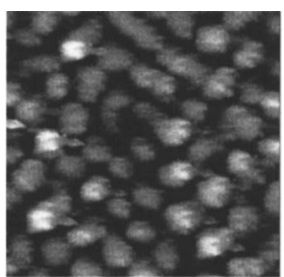

(b)

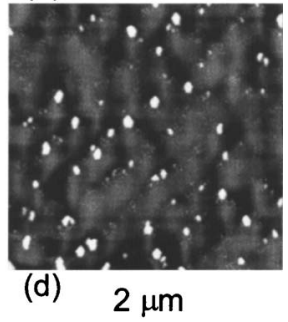

FIG. 5. AFM images of InAs grown at $470{ }^{\circ} \mathrm{C}$ on the ten-period SL template with Al-containing GaAs spacer layers. (a) InAs QDs directly grown on 2 MLs AlAs on the SL template. The black-to-white height contrast is $5 \mathrm{~nm}$. (b) InAs grown on the SL template with 2 MLs AlAs covered by $1.0 \mathrm{~nm}$ GaAs underneath each (In, Ga)As layer in the SL template and the InAs layer on top. The black-to-white height contrast is $10 \mathrm{~nm}$. (c) InAs grown on the SL template with 2 MLs AlAs on each thin GaAs cap layer after annealing. The black-to-white height contrast is $10 \mathrm{~nm}$. (d) InAs grown on the SL template with $\mathrm{Al}_{0.24} \mathrm{Ga}_{0.76} \mathrm{As}$ spacer layers. The black-to-white height contrast is $20 \mathrm{~nm}$. The total spacer layer thickness in the SL template is $5.5 \mathrm{~nm}$ for all samples. The scan field is $2 \times 2 \mu \mathrm{m}^{2}$ for all images.

GaAs spacer layer by $\mathrm{Al}_{0.24} \mathrm{Ga}_{0.76} \mathrm{As}$ produces a low density of InAs QDs together with large InAs clusters, which are randomly distributed on the sample surface [Fig. 5(d)].

The diminished InAs QD ordering in the presence of AlAs in the SL template indicates that a well-defined (In,Ga)As- and strain-field modulation is not established. This is attributed to the low surface migration length of $\mathrm{Al}$ and the reduced surface migration lengths of In [revealed in Fig. 5(a)] and Ga on AlAs, hindering the strain induced materials reorganization. The result of Fig. 5(b) with 2 MLs AlAs covered by $1.0 \mathrm{~nm}$ GaAs beneath the (In,Ga)As SL template layers indicates that a considerable lateral mass transport of $\mathrm{GaAs}$ underneath the $(\mathrm{In}, \mathrm{Ga}) \mathrm{As}$ layers is involved in the formation of the strain modulated (In,Ga)As/ GaAs SL template of Fig. 1, which is hindered by the 2 MLs AlAs layer. The result of Fig. 5(c) with the 2 MLs AlAs deposited on the thin GaAs cap after annealing furthermore indicates that also significant lateral mass transport during GaAs spacer layer growth is essential for building up the strain modulated SL template nodes, which is likewise hindered on AlAs. Finally, for (Al,Ga)As spacer layers [Fig. 5(d)] a two-dimensional mesoscopic ordering is entirely suppressed due to the small surface migration length of Al. It is interesting to note that despite the insertion of thin AlAs layers a two-dimensional mesalike surface morphology is still observed in Figs. 5(b) and 5(c), though with a reduced height, whereas InAs QD ordering is strongly degraded. This underlines the lateral strain field modulation established in Al-free (In,Ga)As/GaAs SL templates to fully govern the InAs QD ordering independent of morphological features. 

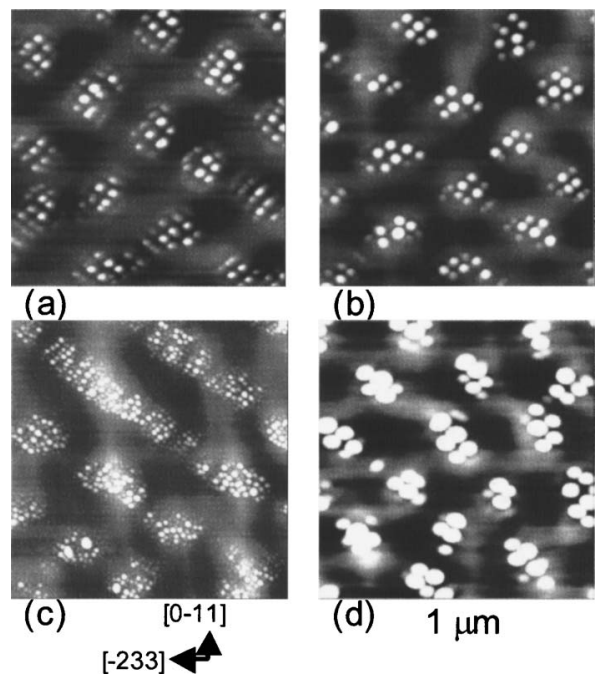

FIG. 6. AFM images of the InAs QD molecules grown at $470{ }^{\circ} \mathrm{C}$ on the ten-period SL template with upper GaAs separation layer thickness of (a) 5.5 , (b) 15, and (c) $20 \mathrm{~nm}$. In (d) the growth temperature of the (In,Ga)As and thin GaAs cap layers in the ten-period SL template with $15 \mathrm{~nm}$ upper GaAs separation layer thickness is increased to $520{ }^{\circ} \mathrm{C}$. The scan field is $1 \times 1 \mu \mathrm{m}^{2}$ and the black-to-white height contrast is $10 \mathrm{~nm}$ for all images.

\section{INAS QD MOLECULES: CONTROLLING THE NUMBER OF QDS}

To control the average number of InAs QDs within the molecules, a reduction of the amount of InAs rather reduces the QD height, leaving the QD number unchanged. This indicates that the growth of the InAs QDs on the SL template rather follows strain induced growth instability than nucleation in the SK mode, which is attributed to the reduced lattice mismatch on the nodes. ${ }^{10}$ The average number of InAs QDs is controlled by the thickness of the upper GaAs separation layer on the SL template. The number is reduced from 11 for the $5.5 \mathrm{~nm}$ thick GaAs separation layer [Fig. 6(a)] to 8.5 for a thickness of $9.5 \mathrm{~nm}$, and to 7.5 for a thickness of 15 $\mathrm{nm}$, depicted in Fig. 6(b). The growth temperature of the 0.5 $\mathrm{nm}$ InAs QDs is $470{ }^{\circ} \mathrm{C}$ for optimized QD ordering within the molecules on the ten-period SL template. The reduction of the average number of QDs per molecule with increasing upper GaAs separation layer thickness on the SL template is attributed to a decrease of the tensile strain field minima, shrinking the effective area for preferred QD formation. When, however, the upper GaAs separation layer thickness is increased to $20 \mathrm{~nm}$, the QD ordering degrades for too shallow strain field minima, shown in Fig. 6(c).

The effective area for QD formation and, thus, the average number of QDs per molecule is further decreased by increasing the (In, Ga)As and thin GaAs cap growth temperature in the SL template, which is attributed to enhanced In migration and In accumulation on the nodes. Figure 6(d) shows the InAs QD molecules deposited at $470{ }^{\circ} \mathrm{C}$ on the ten-period SL template with the (In,Ga)As and thin GaAs cap layers grown at $520^{\circ} \mathrm{C}$ and a $15 \mathrm{~nm}$ thick upper $\mathrm{GaAs}$ separation layer. The average number of QDs per molecule is four. Hence, by adjusting the thickness of the upper GaAs separation layer and the (In, Ga)As growth temperature in the

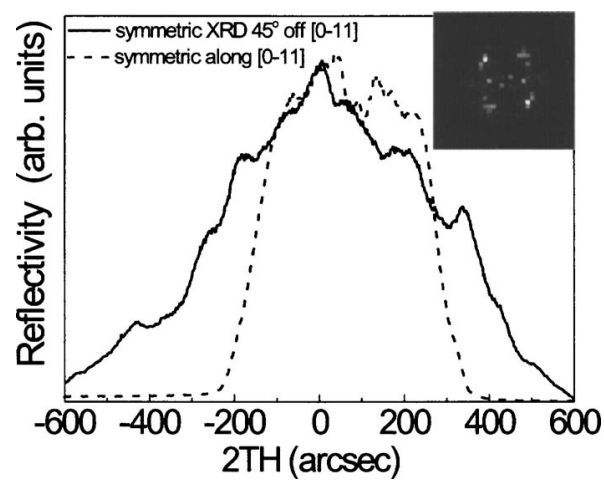

FIG. 7. XRD spectra recorded in the vicinity of the symmetric (311) reflection of the ten-period SL template of Fig. 1(c) without the upper (In,Ga)As layer with the x-ray beam $45^{\circ}$ off (solid line) and along (dashed line) [0-11]. Inset: AFM two-dimensional fast-Fourier transform analysis of the InAs QD molecules on the ten-period SL template.

SL template, well-separated groups of ordered InAs QDs with adjustable number are realized, which are themselves self-organized into an ordered lattice.

\section{X-RAY DIFFRACTION: PROOF OF STRAIN CORRELATION}

High-resolution XRD performed in various scattering geometries consistently confirms the lateral strain field modulation and strain correlated growth in SL template formation and QD ordering. The XRD spectra of the optimized tenperiod SL template of Fig. 1(c) [without the (In,Ga)As layer on top] are recorded in the vicinity of the symmetric (311) reflection with the x-ray beam $45^{\circ}$ off [0-11] and along [0-11], see Fig. 7. Both spectra reveal clear satellite peaks close to the substrate reflection whose spacing provides the periodicity of the lateral strain field modulation of the SL template in the respective directions. ${ }^{14}$ The lateral periodicity along the direction $45^{\circ}$ off [0-11] is $350 \mathrm{~nm}$ and that along $[0-11]$ is $420 \mathrm{~nm}$. For completeness, grazing exit XRD spectra recorded in the vicinity of the asymmetric (004) reflection reveal a lateral periodicity along [0-11] of $400 \mathrm{~nm}$. These values coincide well with the lateral periodicity of the InAs QD molecules on the SL template along the direction $45^{\circ}$ off [0-11] of $300 \mathrm{~nm}$, which is derived from the two-dimensional fast-Fourier transform analysis of the AFM images in Figs. 3(a) and 3(b), see inset in Fig 7.

\section{SINGLE INAS QDS: FORMATION}

To realize single InAs QDs on the nodes of the ten-period SL template, not only the growth temperature of the (In, Ga)As layers in the SL template is increased but also the temperatures for annealing and GaAs spacer layer growth, and that for InAs QD deposition. Figure 8(a) shows the AFM image of the InAs QDs grown at $500{ }^{\circ} \mathrm{C}$ on the SL template with (In,Ga)As and thin GaAs cap growth temperature of $530{ }^{\circ} \mathrm{C}$, and annealing and $\mathrm{GaAs}$ spacer layer growth at $610^{\circ} \mathrm{C}$. The upper GaAs separation layer thickness is $15 \mathrm{~nm}$. The number of InAs QDs on the SL template nodes, however, does not change compared to that in Fig. 6(d) where 


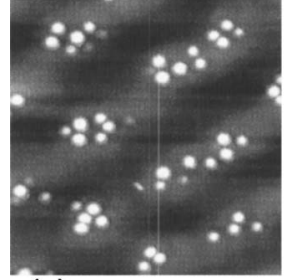

(a)

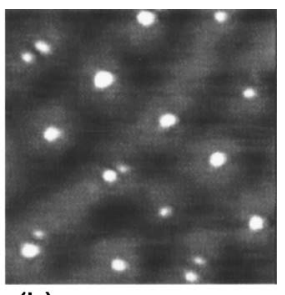

(b)
$1 \mu \mathrm{m}$

FIG. 8. AFM images of the InAs QDs grown at $500^{\circ} \mathrm{C}$ on the ten-period $\mathrm{SL}$ template with growth temperature of $530^{\circ} \mathrm{C}$ of the (In,Ga)As and thin $\mathrm{GaAs}$ cap layers, and $610^{\circ} \mathrm{C}$ for annealing and the GaAs spacer layers. (a) InAs QDs without and (b) with additional InAs QD layers, thin GaAs capped and annealed, on the SL template with a $15 \mathrm{~nm}$ upper GaAs separation layer and overgrown by $15 \mathrm{~nm}$ GaAs. The scan field is $1 \times 1 \mu \mathrm{m}^{2}$ and the black-towhite height contrast is $20 \mathrm{~nm}$ for both images.

only the growth of the (In,Ga)As layers is at a higher temperature. The QD groups are less separated and ordered due to enhanced In desorption, i.e., reduced total strain in SL growth, and a more stripelike pattern with less defined nodes as discussed for the SL template in Fig. 2(c).

Single InAs QDs on the SL template nodes are realized at the elevated growth and annealing temperatures of the tenperiod SL template and InAs QDs when an additional $0.5 \mathrm{~nm}$ InAs QD layer is inserted. ${ }^{9}$ The additional InAs QD layer is grown at $500{ }^{\circ} \mathrm{C}$ on the SL template with $15 \mathrm{~nm}$ upper GaAs separation layer, it is thin GaAs capped and annealed as the (In,Ga)As layers in the SL template, and overgrown by 15 $\mathrm{nm}$ GaAs. Due to the fact that the InAs QDs in this interlayer solely form on the SL template nodes, the lateral strain field modulation most effectively concentrates after thin GaAs capping and annealing. Together with the enhanced In adatom migration length at elevated temperature, supported by the tendency for QD coalescence [discussed for the case of Fig. 3(a)], the resulting shrinkage of the effective area of the tensile strain field minima for preferred QD formation produces single InAs QDs in the center of the nodes, as shown in Fig. 8(b). Only the combination of elevated temperatures for SL template formation and InAs QD growth and the insertion of an additional InAs QD layer realizes single QDs. Applied separately, the average QD number per molecule is not changed significantly.

\section{OPTICAL PROPERTIES: PL EFFICIENCY AND TEMPERATURE DEPENDENCE}

The high structural and optical quality of the InAs QD molecules manifests itself in the excellent PL properties up to RT. Figure 9 shows the PL spectra taken at $5 \mathrm{~K}$ and RT of the capped InAs QDs of Fig. 6(b). At $5 \mathrm{~K}$ the peak at $1.18 \mathrm{eV}$ with a FWHM of $60 \mathrm{meV}$ originates from the InAs QDs and that at $1.32 \mathrm{eV} \mathrm{nm}$ (FWHM $44 \mathrm{meV}$ ) from the SL template. The PL of the SL and QDs is well separated due to In desorption and flattening of the (In, Ga)As layers during annealing. ${ }^{13}$ At RT the PL of the QDs is centered at $1.10 \mathrm{eV}$ with a FWHM of $60 \mathrm{meV}$ and a three orders of magnitude reduced peak efficiency. The absence of RT PL from the SL

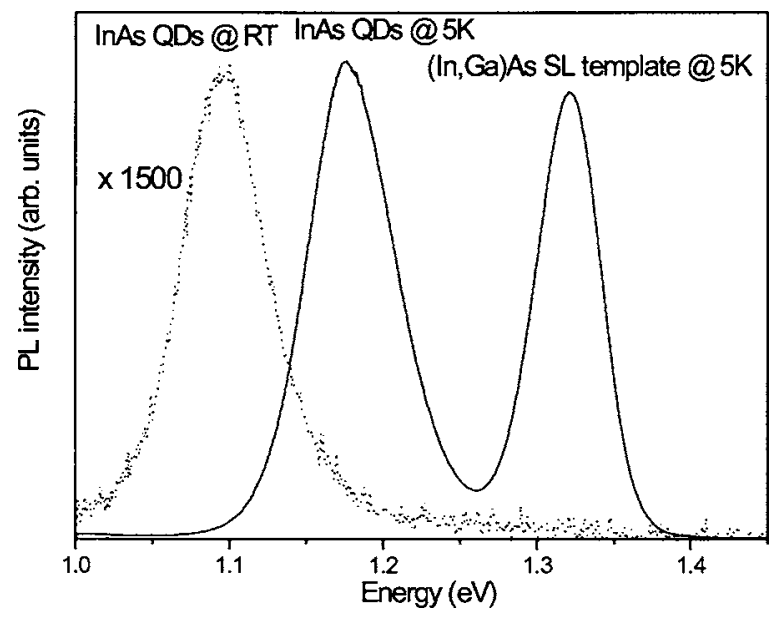

FIG. 9. PL spectra taken at $5 \mathrm{~K}$ (solid line) and RT (dotted line) of the capped InAs QD molecules grown at $470{ }^{\circ} \mathrm{C}$ on the ten-period SL template with $15 \mathrm{~nm}$ upper GaAs separation layer.

template indicates efficient carrier transfer to the QDs. Most important, the PL efficiency of the QD molecules is not degraded compared to that of InAs QDs directly grown on GaAs with comparable FWHM.

Detailed temperature dependent PL measurements between $5 \mathrm{~K}$ and RT reveal a constant value of the FWHM of the QD molecules up to $80 \mathrm{~K}$, shown in Fig. 10(a). The FWHM then undergoes a distinct minimum at $140 \mathrm{~K}$ due to thermally activated redistribution of carriers preferentially from smaller (higher energy) to larger (lower energy) QDs. ${ }^{15}$ This is accompanied by a characteristic enhancement of the low-energy shift of the PL peak position as a function of temperature, depicted in Fig. 10(b). The FWHM increases steeply to $57 \mathrm{meV}$ at $190 \mathrm{~K}$ due to equilibration of the carrier distribution in large and small QDs when the probability of carrier escape from the large QDs increases. Remarkably, the steep increase of the FWHM is followed by a very weak increase above $190 \mathrm{~K}$ to a value of $59 \mathrm{meV}$ at RT. The distinct inflection point at $190 \mathrm{~K}$ indicates equilibration of the carrier redistribution solely within the QD molecules, which is followed by thermal broadening resembling that of isolated QDs. ${ }^{16}$ This indicates that the QD molecules are electronically isolated. Such an unusual behavior of the FWHM is not observed for the capped (In, Ga)As QD layer of Fig. 1(c) and for the SL template of Fig. 1(c) without an upper (In,Ga)As layer, shown in Fig. 10(a) for reference. After the minimum of the FWHM and enhanced low-energy shift of the PL peak position [Fig. 10(b)] due to thermally activated carrier redistribution, the FWHM continuously increases with temperature, which is attributed to a continuous increase of the carrier spread over areas fully covered with QDs.

\section{CONCLUSIONS}

In conclusion, highly ordered lateral InAs quantum dot (QD) molecules have been created by self-organized anisotropic strain engineering of a $(\mathrm{In}, \mathrm{Ga}) \mathrm{As} / \mathrm{GaAs}$ superlattice (SL) template on GaAs (311)B substrates by molecular beam 
(a)

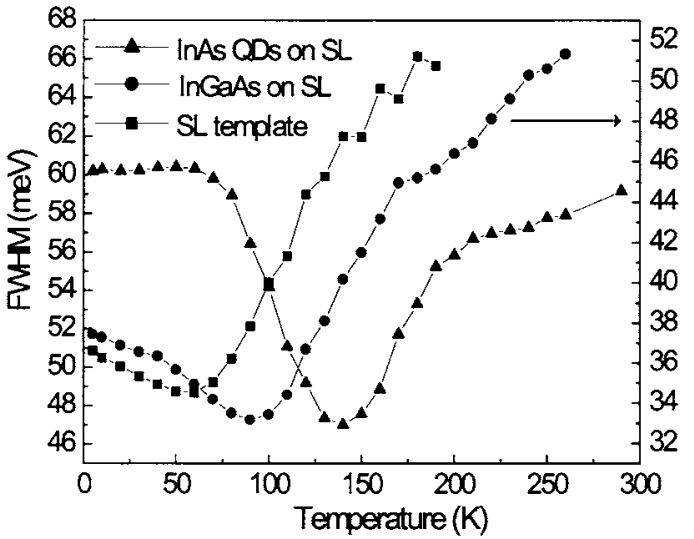

(b)

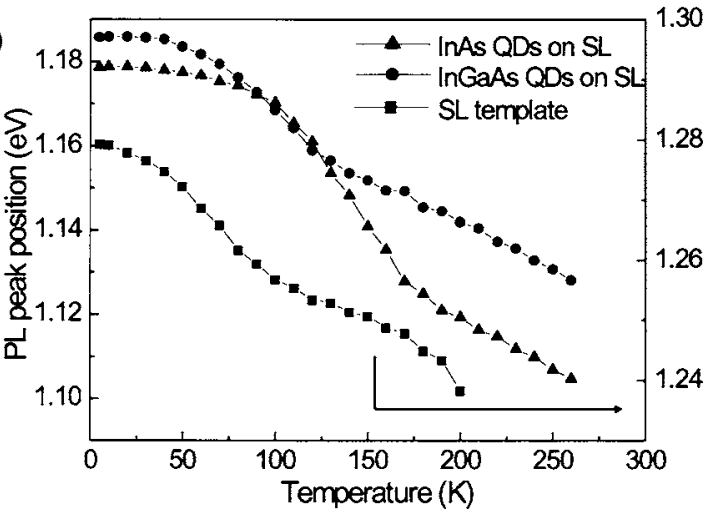

FIG. 10. Temperature dependence of (a) the full width at half maximum (FWHM) and (b) the PL peak position of the capped InAs QD molecules of Fig. 6(b) (solid triangles), the capped (In,Ga)As QDs of Fig. 1(c) (solid circles), and the ten-period SL template of Fig. 1(c) without the upper (In,Ga)As layer (solid squares).

epitaxy (MBE). During stacking the SL template selforganizes into a two-dimensionally ordered (In,Ga)As and, thus, strain field modulation on a mesoscopic length scale due to anisotropic surface migration and strain-correlated growth; constituting a Turing pattern in solid state. InAs QDs preferentially grow on top of the SL template nodes due to local strain recognition. They form well-separated groups of ordered and closely spaced QDs, which are themselves selforganized into an ordered lattice. The SL template and InAs QD growth conditions like the number of SL periods, growth temperatures, amount and composition of deposited (In, Ga)As, and insertion of Al-containing layers have been varied for optimized InAs QD ordering within and among the QD molecules, as evaluated by atomic force microscopy (AFM). The average number of QDs per molecule has been controlled by the upper GaAs separation layer thickness on the SL template and the growth temperature of the (In, Ga)As layers in the SL template. The strain correlated growth in SL template formation and QD ordering has been consistently confirmed by high-resolution x-ray diffraction (XRD) in various scattering geometries. Single InAs QDs on the SL template nodes have been realized at elevated temperatures for SL template formation and InAs QD growth together with the insertion of an additional InAs QD layer. The optical properties of the QD molecules are excellent up to room temperature. Temperature dependent photoluminescence (PL) measurements have revealed an unusual behavior of the full width at half maximum indicating carrier redistribution solely within the QD molecules. Hence, fascinating applications of our InAs QD molecules created by self-organized anisotropic strain engineering on GaAs (311)B are foreseen for quantum functional devices in the field of quantum computing and quantum communication in solid state.

${ }^{1}$ R. Nötzel, T. Mano, Q. Gong, and J. H. Wolter, Proc. IEEE 91, 1898 (2003).

${ }^{2}$ T. Ishikawa, T. Nishimura, S. Kohmoto, and K. Asakawa, Appl. Phys. Lett. 76, 167 (2000).

${ }^{3}$ H. Lee, J. A. Johnson, M. Y. He, J. S. Speck, and P. M. Petroff, Appl. Phys. Lett. 78, 105 (2001).

${ }^{4}$ Y. Nakamura, O. G. Schmidt, N. Y. Jin-Phillipp, S. Kiravittaya, C. Müller, K. Eberl, H. Gräbeldinger, and H. Schweizer, J. Cryst. Growth 242, 339 (2002).

${ }^{5}$ T. Mano, R. Nötzel, G. J. Hamhuis, T. J. Eijkemans, and J. H. Wolter, Appl. Phys. Lett. 81, 1705 (2002).

${ }^{6}$ T. Mano, R. Nötzel, G. J. Hamhuis, T. J. Eijkemans, and J. H. Wolter, J. Appl. Phys. 95, 109 (2004).

${ }^{7}$ Z. M. Wang, K. Holmes, Yu. I. Mazur, and G. J. Salamo, Appl. Phys. Lett. 84, 1931 (2004).

${ }^{8}$ T. v. Lippen, R. Nötzel, G. J. Hamhuis, and J. H. Wolter, Appl. Phys. Lett. 85, 118 (2004).

${ }^{9}$ T. v. Lippen, R. Nötzel, G. J. Hamhuis, and J. H. Wolter, Appl. Phys. Lett. 97, 044301 (2005).

${ }^{10}$ Q. Gong, R. Nötzel, G. J. Hamhuis, T. J. Eijkemans, and J. H. Wolter, Appl. Phys. Lett. 81, 3254 (2002).

${ }^{11}$ J. Temmyo, R. Nötzel, and T. Tamamura, Appl. Phys. Lett. 71, 1086 (1997).

${ }^{12}$ R. Nötzel, J. Temmyo, and T. Tamamura, Nature (London) 369, 131 (1994).

${ }^{13}$ T. Leppänen, M. Karttunen, R. A. Barrio, and K. Kaski, Phys. Rev. E 70, 066202 (2004).

${ }^{14}$ T. Mano, R. Nötzel, G. J. Hamhuis, T. J. Eijkemans, and J. H. Wolter, J. Appl. Phys. 92, 4043 (2002)

${ }^{15}$ D. I. Lubyshev, P. P. Gonzalez-Borrero, E. Marega, Jr., E. Petitprez, N. La Scala, Jr., and P. Basmaji, Appl. Phys. Lett. 68, 205 (1996).

${ }^{16}$ I. Favero, G. Cassabois, R. Ferreira, D. Darson, C. Voisin, J. Tignon, C. Delalande, G. Bastard, Ph. Roussignol, and J. M. Gérard, Phys. Rev. B 68, 233301 (2003). 